\title{
Toxicity and teratogenicity in zebrafish Danio rerio embryos exposed to chromium
}

\author{
Marco Antonio Sánchez-Olivares ${ }^{1}\left(\mathbb{D}\right.$, Juan Carlos Gaytán-Oyarzun ${ }^{1}\left(\mathbb{D}\right.$, Alberto José Gordillo-Martínez ${ }^{2}$ (b) \\ Francisco Prieto-Garcia ${ }^{2}$ \& René Bernardo Elías Cabrera-Cruz ${ }^{3}$ \\ ${ }^{1}$ Área Académica de Biología, Universidad Autónoma del Estado de Hidalgo \\ Pachuca, Hidalgo, México \\ ${ }^{2}$ Área Académica de Química, Universidad Autónoma del Estado de Hidalgo \\ Pachuca, Hidalgo, México \\ ${ }^{3}$ Facultad de Ingeniería “Arturo Narro Siller”, Universidad Autónoma de Tamaulipas \\ Centro Universitario Sur Tampico, Tamaulipas, México \\ Corresponding author: Juan Carlos Gaytán-Oyarzun (jcgaytan@uaeh.edu.mx)
}

\begin{abstract}
Chromium $(\mathrm{Cr})$ is an element present in nature in mineral form. It has a dual effect, both as an essential micronutrient and a carcinogenic agent depending on its chemical form and concentration. It is present in various environmental matrices such as water, soil, and air, coming from natural and anthropogenic sources, and causes harmful effects on biota, ecosystems, and even human beings. This study's objective was to evaluate chromium toxicity and teratogenicity in zebrafish embryos of Danio rerio exposed to chromium through the $D$. rerio teratology assay (DarTA) test by evaluating spine malformations. To this end, the chromium toxicity curve was calculated from zebrafish embryos exposed to potassium dichromate $\left(\mathrm{K}_{2} \mathrm{Cr}_{2} \mathrm{O}_{7}\right)$, and the probit test was used to establish the mean lethal concentration $\left(\mathrm{LC}_{50}\right)$ and three subtoxic concentrations $\mathrm{LC}_{25}, \mathrm{LC}_{12.5}$, and $\mathrm{LC}_{6.25}$ to evaluate the teratogenicity. The results showed that potassium dichromate was statistically positive for the teratogenic effect at the three highest concentrations evaluated. Potassium dichromate exposure causes abnormal embryonic development and teratogenic effects, including severe heart defects in zebrafish embryos. Therefore, we conclude that potassium dichromate is toxic to the zebrafish developmental stages. The finding that potassium dichromate is teratogenic in zebrafish embryos suggests that this metal should be tested and evaluate potential risk in mammalian systems.
\end{abstract}

Keywords: Danio rerio; embryos; malformations; chromium; teratogenicity; embryonic development

\section{INTRODUCTION}

Chromium (Cr) is considered a hazardous element and is listed among the eight most common heavy metal pollutants by the USA Environmental Protection Agency (USEPA 2010). This element is a group 1 carcinogen classified by the International Agency for Research on Cancer (IARC 1990). Chromium is a naturally occurring element found in several environmental matrices (water, soil, and air). It is released to the environment in its hexavalent form [Cr (VI)], from natural and anthropogenic sources (Velma et al. 2009), such as metal processing, tannery facilities, chromate production, pigments, and batteries (OECD 2004,
USEPA 2010). The oxidation states range from $[\mathrm{Cr}$ $(-\mathrm{II})]$ to $[\mathrm{Cr}(+\mathrm{VI})]$, the most predominant being the trivalent (III) and hexavalent (VI) stages (Valko et al. 2005, Lushchak et al. 2008, USEPA 2010). Trivalent state of chromium [Cr (III)] being a non-toxic form is not considered as an environmental pollutant, but hexavalent chromium [Cr (VI)] due to its potential to be readily absorbed by the cell, is more toxic and is a matter of concern (WHO 2003, Guertin 2005, Shaw et al. 2019).

Chromium is frequently used as a chemical model in ecotoxicological studies and as a reference toxicant (OECD 2004). Previous studies demonstrated that chromium could induce histological and morphological

Corresponding editor: Eduardo Ballester 
alterations in organs (Begum et al. 2006, Mishra \& Mohanty 2008), developmental effects (ATSDR 2000), genotoxicity (Shaw et al. 2019), metabolism alterations (Begum et al. 2006, Oner et al. 2008), and DNA damage (Qi et al. 2000, De Lemos et al. 2001, Normann et al. 2008). To understand the action mechanisms and toxicological effects of chemical compounds, the application of biological tests has been widespread (Bambino \& Chu 2016). Biological tests provide baseline information that can be used to assess the risks of chemical agents to the body under various exposure conditions (Rinkwitz et al. 2011, Zada et al. 2014). In this context, zebrafish Danio rerio provide an ideal model to study these effects.

Zebrafish has been extensively studied, described, and used as a model organism in ecotoxicology to assess the effects of chemicals and their risk to the environment (Kimmel et al. 1990, Domingues et al. 2010). The zebrafish characteristics, such as external fertilization, rapid embryonic development (Zhang et al. 2003, Lieschke \& Currie 2007), and optical transparency, have made it a model of research allowing to study their morphological endpoints including developmental (evaluating anomalies and delays of embryo development) (Hill et al. 2005, Oliveira et al. 2009, Domingues et al. 2010, Yang et al. 2011, Li et al. 2014, Van Houcke et al. 2015). Their high sensitivity allows the identification of a potential hazard. It provides information on the toxic and teratogenic effects of chemicals (Zhu et al. 2004, McCollum et al. 2011), being an important tool in risk prevention (Domingues et al. 2010, Pica-Granados et al. 2011, Howe et al. 2013). Zebrafish provides technical and scientific advantages that allow it to be considered an appropriate model for detecting toxicity in embryonic development.

In the present study, the D. rerio teratology assay test (DarTA) (Nagel 2002, Gaytán et al. 2008) was used to assess the toxicity and zebrafish embryos teratogenicity. DarTA is a test that evaluates, at different concentrations, the teratogenic effect of chemicals during embryonic development, recording morphological abnormalities such as malformation in the spine, operculum, fin, and cardiac alterations (yolk sac edema and pericardial edema) (Nagel 2002, Gaytán et al. 2008, Weil et al. 2009, Weigt et al. 2010). Therefore, this study's objective was to evaluate the toxicity and teratogenicity in zebrafish embryos of $D$. rerio exposed to chromium through the DarTA test.

\section{MATERIAL AND METHODS}

\section{Bioassay}

One hundred fifty zebrafish Danio rerio were maintained at the Biological Research Center of the
Autonomous University of Hidalgo State, Mexico, acclimated for two weeks, and kept into a 70-L tank at a temperature of $27 \pm 1^{\circ} \mathrm{C}$; provided with the optimal physicochemical conditions for fish development. The tank was equipped with a $100 \mathrm{w}$ automatic heater and a $10 \mathrm{w}$ AquaJet ${ }^{10 \mathrm{~F}}$ filter with a capacity of $480 \mathrm{~L} \mathrm{~h}^{-1}$ (Rivera 2006). Fishes were kept under $12 \mathrm{~h}$ light photoperiod and $12 \mathrm{~h}$ of darkness (Gaytán et al. 2008). During the maintenance period (3 weeks), they were fed three times a day with dry food, adding commercial food flakes $\left(\right.$ Lomas $\left.^{\circledR}\right)$ with a raw protein content of $43 \%$, 5\% raw fat, 3\% raw fiber, and $200 \mathrm{mg} \mathrm{kg}^{-1}$ vitamin C. Uneaten food was removed three times a day to avoid contamination with fungi and protozoa (Oberamm 2000). Healthy adult male and female fishes (3:2 ratio, respectively) were placed in a $40 \mathrm{~L}$ spawning tank equipped with a maternity mesh. Forty-eight males and 32 females were maintained to induce spawning according to a maximal embryo production method (Westerfield 2007). The fertilized embryos were transferred into a clean crystallizer to avoid contamination by adult feces and food remains (Gaytán et al. 2008). The embryos were then staged according to Kimmel et al. (1995) under a stereoscopic microscope and removed any unfertilized or dead embryos.

\section{Toxicity test}

Potassium dichromate $\left(\mathrm{K}_{2} \mathrm{Cr}_{2} \mathrm{O}_{7}\right)$ (JT Baker, CAS number 7778-50-9) was used as the source of chromium. Stocks solutions $\left(10 \mathrm{~g} \mathrm{~L}^{-1}\right)$ were prepared by dissolving potassium dichromate in water, and test solutions were obtained by diluting the stock. Toxicity tests were designed according to Gaytán et al. (2008). Ten concentrations of potassium dichromate $(0.00625$, $0.0125,0.025,0.0375,0.050,0.0565,0.0625,0.075$, 0.0875 and $0.1 \mathrm{mg} \mathrm{L}^{-1}$ ) were chosen to evaluate the toxicity of potassium dichromate, and determine the mean lethal concentration $\left(\mathrm{LC}_{50}\right)$. Three groups of zebrafish embryos $(n=30)$ were exposed to each potassium dichromate concentration. The test ran for 72 $\mathrm{h}$ until the embryos hatched, and the percentage of mortality per concentration were calculated. Mortality data were analyzed by using the probit test, and the $\mathrm{LC}_{50}$ was established.

\section{Teratogenicity test}

In this study, $72 \mathrm{~h} \mathrm{LC}_{50}$ of potassium dichromate was established as the highest ex perimental concentration to evaluate teratogenic effects without the toxicity of potassium dichromate obscuring these effects (González 2005, Rivera 2006, Gaytán et al. 2008). Median lethal concentration served as a criterion for selecting three experimental subtoxic concentrations $\left(\mathrm{LC}_{25}, \mathrm{LC}_{12.5}, \mathrm{LC}_{6.25}\right)$, which were set up to evaluate the 
potassium dichromate effect on zebrafish embryos teratogenicity.

Once the $\mathrm{LC}_{50}$ and subtoxic concentrations were established, the teratogenic effect was evaluated using the spinal damage biomarker (Gaytán et al. 2008). For this, 450 embryos were used per concentration at approximately $2-4 \mathrm{~h}$ post-fertilization (hpf); only the fertilized eggs were selected and distributed in 15 glass bottles of $125 \mathrm{~mL}$, with 30 embryos per concentration (Rivera 2006). Each bottle contained $100 \mathrm{~mL}$ of $\mathrm{K}_{2} \mathrm{Cr}_{2} \mathrm{O}_{7}$ solution, corresponding to the proximal concentrations of $\mathrm{LC}_{50}, \mathrm{LC}_{25}, \mathrm{LC}_{12.5}, \mathrm{LC}_{6.25}$, and a control bottle of 450 embryos in water free of contaminant. Exposure to the chemical compound lasted $72 \mathrm{~h}$ post-fertilization (hpf) until the embryos hatched. The observation should be made at the time of hatching, being more evident in the spine's alterations at the end of the embryogenesis (Gaytán et al. 2008). Subsequently, the fish's development was observed directly in Petri dishes using a stereoscopic microscope equipped with a 40x auxiliary lens. Two thousand two hundred and fifty embryos were analyzed, and the frequencies of malformations were counted and identifying as early and late according to the expression time.

\section{Frequency analysis of malformations}

For the evaluation of malformations, we classified the biomarker of spinal damage, which consists of dividing the organism's body into three zones to identify the damage: cephalic, central, and caudal (Fig. 1). The types of malformations are classified according to time as early (spiral, caudal spiral, square, hook, and absence of body) or late (simple, double, multiple, curves, caudal fin). Morphological alterations at the heart level were pericardial edema, and yolk sac edema was also recorded (González 2005, Rivera 2006, Gaytán et al. 2008).

\section{Statistical analysis}

Probit analysis was used to determine the median lethal concentration $\left(\mathrm{LC}_{50}\right)$, calculated using the probit test, to analyze the relationship between a stimulus (dose) and the response (death) (IBM Corp. 2017). An $\chi^{2}$ test was carried out on the malformation frequency data to identify significant differences between treatments, and a correspondence analysis was carried out to determine the association between the type of malformations and the concentrations.

\section{RESULTS}

In the present study, zebrafish Danio rerio embryos were exposed to several concentrations of $\mathrm{K}_{2} \mathrm{Cr}_{2} \mathrm{O}_{7}$ for

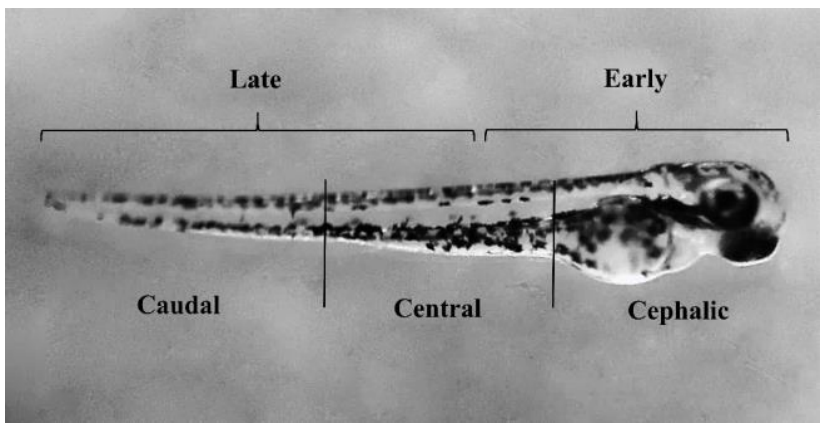

Figure 1. Division of the body of Danio rerio according to the classification of the vertebral column biomarker. Photo by M.A. Sánchez-Olivares.

$72 \mathrm{~h}$. The percentage of mortality increased as the concentration of potassium dichromate administrated increased (Table 1). The probit test calculated $\mathrm{LC}_{50}$ as $0.065 \mathrm{mg} \mathrm{L}^{-1}$ and estimated the $95 \%$ confidence limit as 0.056 to $0.073 \mathrm{mg} \mathrm{L}^{-1}$. From the $\mathrm{LC}_{50}\left(0.065 \mathrm{mg} \mathrm{L}^{-1}\right)$, three teratogenesis experimental subtoxic concentrations were obtained; $\mathrm{LC}_{25}\left(0.047 \mathrm{mg} \mathrm{L}^{-1}\right), \mathrm{LC}_{12.5}(0.037 \mathrm{mg}$ $\left.\mathrm{L}^{-1}\right)$, and $\mathrm{LC}_{6.25}\left(0.018 \mathrm{mg} \mathrm{L}^{-1}\right)$. According to the $\chi^{2}$ test, the concentrations $0.037,0.047$, and $0.065 \mathrm{mg} \mathrm{L}^{-1}$ showed significant differences $(P<0.001)$ concerning the control group, confirming the teratogenic effect of the compound (Table 2).

The correspondence analysis explained $85.01 \%$ of the cumulative variance in the first two dimensions; D1 and D2 explained 52.10 and $32.91 \%$, respectively. Figure 2 details the combination of dimensions 1 and 2, and four defined groups can be observed. The first association corresponds to samples $\mathrm{LC}_{25}$, double, and multiple. The second, to samples $\mathrm{LC}_{12.5}, \mathrm{LC}_{6.25}$, simple, curved, absence of the body, and spiral. The third association corresponds to samples $\mathrm{LC}_{50}$ and hook. The fourth association corresponds to the square samples, caudal fin, caudal spiral, and $\mathrm{H}_{2} \mathrm{O}$ control, due to the low frequency of these types of malformations associated with the control group.

Comparing the expression time, late malformations expressed during the embryo hatching process were more frequent than early malformations expressed in the early stages of embryonic development (Fig. 3). Potassium dichromate caused an increase in malformation frequency in zebrafish embryos, showing a dose-response relationship. Figure 4 shows the types of early malformations, which are expressed in the early stages of embryonic development: these are: a) embryo without malformations, b) hook: the fry has a fold in the central or caudal area giving a hook-like appearance, c) spiral: a spiral twist in the body of the fry, d) spiral flow: a twist in the flow zone, e) square: a lateral or dorsal double in the central zone, at an angle of $90^{\circ}$, 
Table 1. Dose-response values were obtained from a 72-days test with zebrafish Danio rerio embryos exposed to different concentrations of potassium dichromate. n: number of embryos, SD: standard deviation.

\begin{tabular}{lcccc}
\hline $\begin{array}{l}\text { Concentration } \\
\left(\mathrm{mg} \mathrm{L}^{-1}\right)\end{array}$ & $\mathrm{n}$ & Mortality & $\begin{array}{c}\text { Mortality } \\
\%\end{array}$ & Mean $\pm \mathrm{SD}$ \\
\hline 0.1 & 90 & 88 & 93.33 & $29.67 \pm 12.5$ \\
0.0875 & 90 & 78 & 82.22 & $27.67 \pm 13.32$ \\
0.075 & 90 & 63 & 65.56 & $22.67 \pm 10.97$ \\
0.0625 & 90 & 49 & 50.00 & $16.33 \pm 14.74$ \\
0.0565 & 90 & 48 & 48.89 & $16.00 \pm 12$ \\
0.05 & 90 & 42 & 42.22 & $14.00 \pm 13.75$ \\
0.0375 & 90 & 45 & 45.56 & $15.33 \pm 9.61$ \\
0.025 & 90 & 36 & 35.56 & $12.00 \pm 9$ \\
0.0125 & 90 & 24 & 22.22 & $8.00 \pm 9.14$ \\
0.00625 & 90 & 14 & 11.11 & $4.67 \pm 7.23$ \\
Control & 90 & 4 & 4.44 & $1.33 \pm 2.31$ \\
\hline
\end{tabular}

Table 2. Frequency of malformations observed in treatments with potassium dichromate. n: number of embryos; SD: standard deviation; H: hook, Sp: spiral, CS: caudal spiral, Sq: square, Abs: absence of body, S: simple, D: double, M: multiple, C: curve, CF: caudal fin. $* \chi^{2}$ test corrected by $\mathrm{X}_{\mathrm{i}}^{+1} ;(+)$ positive.

\begin{tabular}{|c|c|c|c|c|c|c|c|c|c|c|c|c|c|}
\hline \multirow{3}{*}{$\begin{array}{l}\text { Concentration } \\
\left(\mathrm{mg} \mathrm{L}^{-1}\right)\end{array}$} & \multirow{3}{*}{$\mathrm{n}$} & \multirow{3}{*}{ Mean \pm SD } & \multicolumn{11}{|c|}{ Malformations in the spine } \\
\hline & & & \multicolumn{5}{|c|}{ Early } & \multicolumn{5}{|c|}{ Late } & \multirow{2}{*}{ Total } \\
\hline & & & $\mathrm{H}$ & $\mathrm{Sp}$ & $\mathrm{CS}$ & $\mathrm{Sq}$ & Abs & $\mathrm{S}$ & $\mathrm{D}$ & $\mathrm{M}$ & $\mathrm{C}$ & $\mathrm{CF}$ & \\
\hline $\mathrm{LC}_{50}(0.065)^{*}$ & 450 & $8.4 \pm 7.9$ & $12+$ & $3+$ & $1+$ & $1+$ & $7+$ & $21+$ & $3+$ & $5+$ & $21+$ & 0 & $74+$ \\
\hline $\operatorname{LC}_{25}(0.047) *$ & 450 & $7.1 \pm 7.2$ & 0 & $2+$ & 0 & 0 & $4+$ & $17+$ & $7+$ & $14+$ & $17+$ & 0 & $61+$ \\
\hline $\mathrm{LC}_{12.5}(0.037)^{*}$ & 450 & $3.5 \pm 2.8$ & $2+$ & 0 & 0 & 0 & $2+$ & $7+$ & $3+$ & $5+$ & $6+$ & 0 & $24+$ \\
\hline $\mathrm{LC}_{6.25}(0.018)$ & 450 & $1.6 \pm 2.8$ & 0 & 1 & 0 & 0 & 1 & 9 & 0 & 2 & 3 & 0 & 16 \\
\hline Control $\mathrm{H}_{2} \mathrm{O}$ & 450 & 0 & 0 & 0 & 0 & 0 & 0 & 0 & 0 & 0 & 0 & 0 & 0 \\
\hline Total type of malformations & & & 14 & 6 & 1 & 1 & 14 & 54 & 13 & 26 & 47 & 0 & 175 \\
\hline
\end{tabular}

f) absence of body: the fry lacks some part of the body and is still alive.

Figure 5 shows the types of late malformations that are expressed during the embryo hatching process: a) no malformation: a healthy fry is observed, b) simple: the fry has a fold, either lateral or dorsal, c) doubles: the fry has two folds, either lateral or dorsal, in different areas of the body, d) multiple: the fry has three or more folds in different areas of the body, either lateral or dorsal, e) curves: the fry has a lateral curvature, which causes the fry to swim in a circle, f) caudal fin: the fry has a small fold in the caudal fin.

\section{DISCUSSION}

This research evaluated the toxicity and teratogenicity of chromium in zebrafish (Danio rerio). Embryos mortality was dependent on the potassium dichromate concentrations, indicating that potassium dichromate has a lethal effect on zebrafish embryos. The $72 \mathrm{~h} \mathrm{LC}_{50}$ value in this experiment was $0.065 \mathrm{mg} \mathrm{L}^{-1}$. According to the main test results, embryos exposed to 0.018 and $0.047 \mathrm{mg} \mathrm{L}^{-1}$ presenting five and six types of spine malformations, respectively. Embryos exposed to 0.047 and $0.065 \mathrm{mg} \mathrm{L}^{-1}$, showing six to nine types of spine malformations, and presented a high incidence of pericardial and yolk sac edemas.

In this study, potassium dichromate is associated with damage in the spine and skeletal system of zebrafish embryos. Following Sfakianakis et al. (2006), some of the most common deformities can be located in the vertebral column. Among the malformations induced in zebrafish embryos exposed to potassium dichromate include spinal curvature and skeletal deformities being the most pronounced. In the early embryonic development stages (early malformations), the first contact with the potassium dichromate showed severe malformations such as hook, spiral, caudal spiral, square, and body absence. The presence of this type of abnormalities occurs between the cephalic and central zones, compromising the survival of the embryos; in contrast to malformations occurring in the late stages of embryonic development (late malformations) 


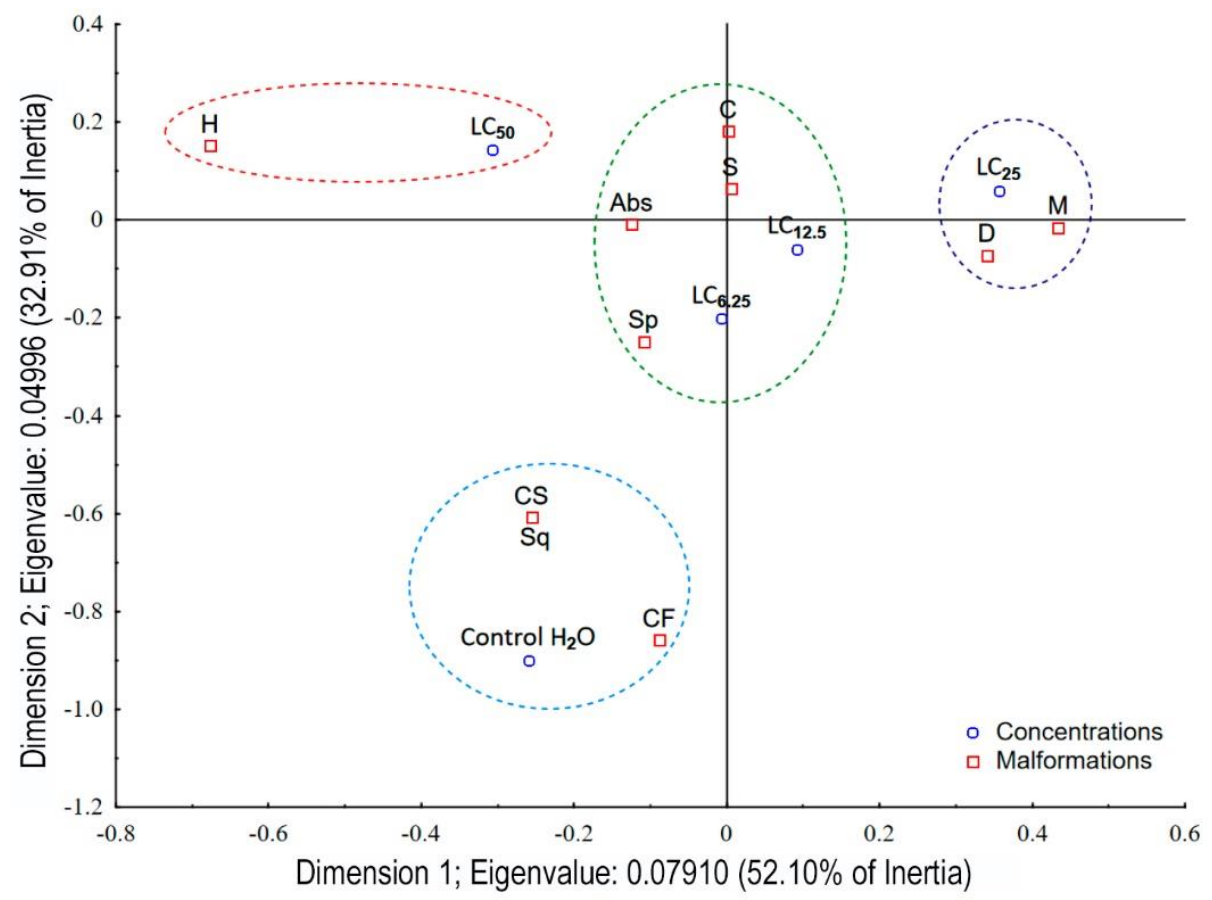

Figure 2. Correspondence analysis combination of dimensions. S: simple, D: double, M: multiple, C: curve, CF: caudal fin, H: hook, Sp: spiral, CS: caudal spiral, Sq: square, Abs: absence of body.

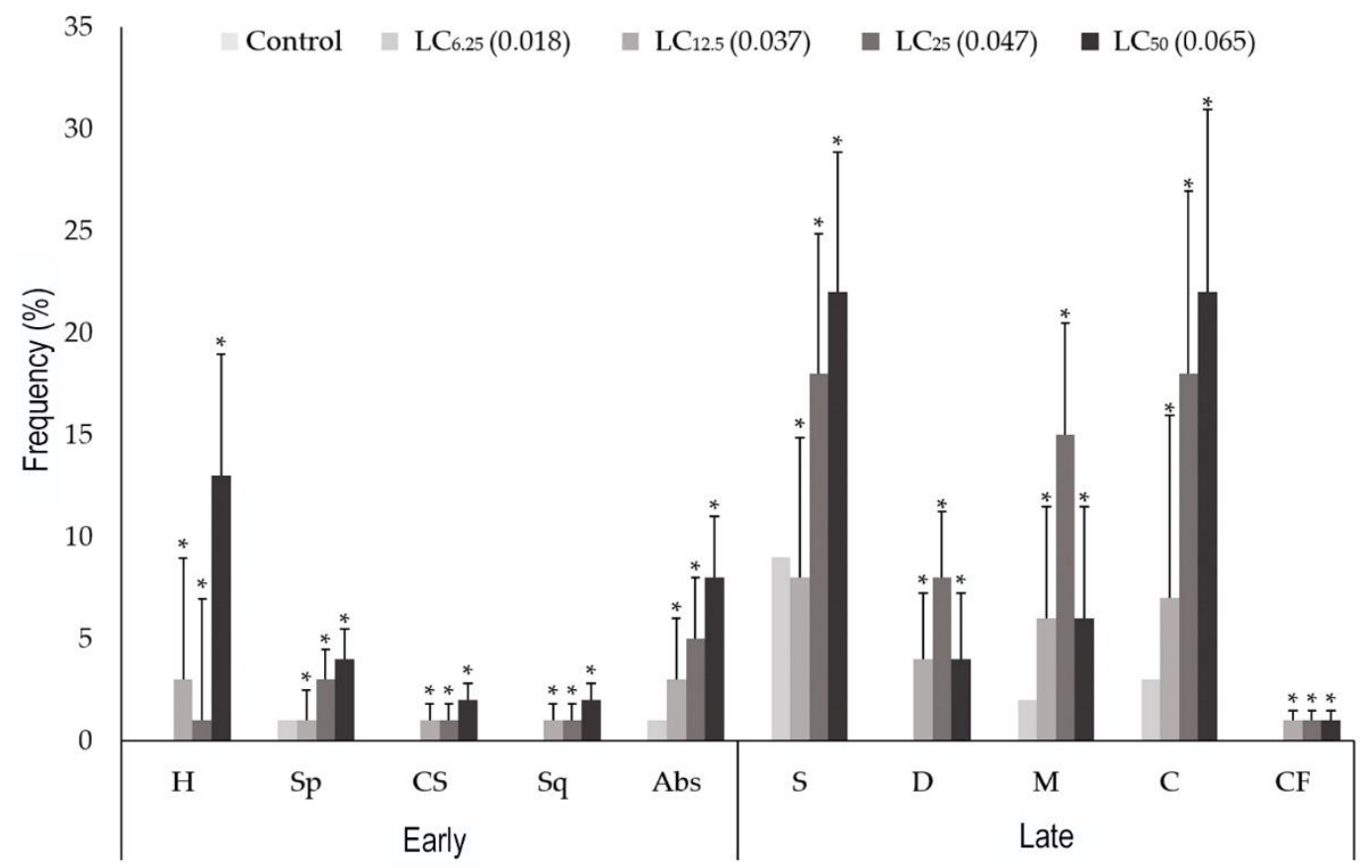

Figure 3. Malformations frequency at $72 \mathrm{hpf}$ of exposure to $\mathrm{K}_{2} \mathrm{Cr}_{2} \mathrm{O}_{7}$. H: hook, Sp: spiral, CS: caudal spiral, Sq: square, Abs: absence of body, S: simple, D: double, M: multiple, C: curve, CF: caudal fin. Data are presented as mean \pm standard error, and significant differences $(P<0.001)$ to the control group are marked $\left(^{*}\right)$.

such as simple, double, multiple, curved, and caudal fin, occurring in the caudal zone of embryos. Samson \& Shenker (2000) note that the severity of abnormalities found in zebrafish embryos indicates more extended exposure periods that induce more severe abnormalities, corroborating this study's findings. Jezierska et al. (2009) mention that the initial embryonic development period after fertilization is the 


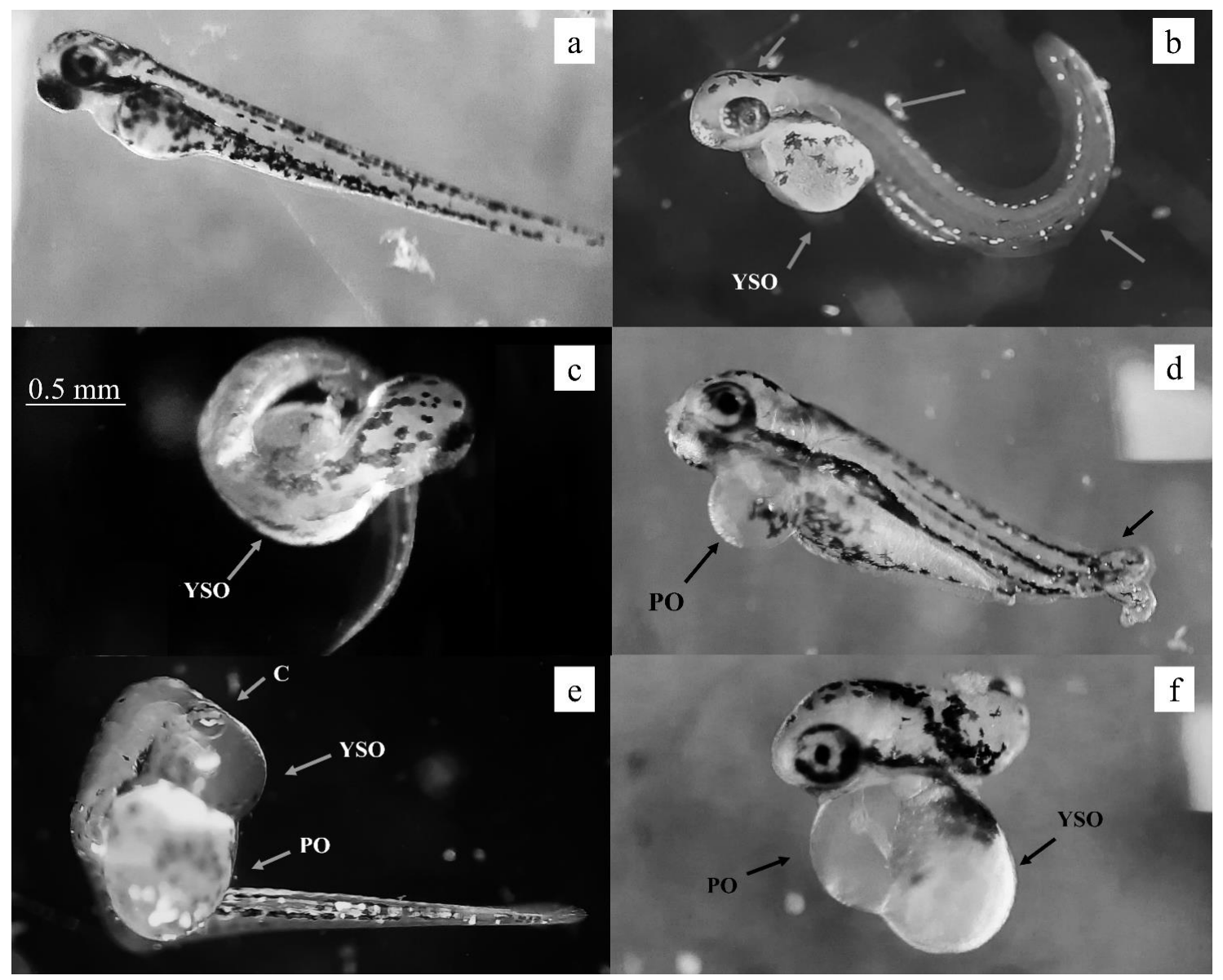

Figure 4. Early malformations in zebrafish (Danio rerio) embryos. PO: pericardial edema, YSO: yolk sac edema, C: cyclops. a) Embryo with normal development, b) hook malformation with yolk sac edema, c) spiral malformation with yolk sac edema, d) spiral malformation with pericardial edema, e) squadron malformation with pericardial edema cyclops and absence of fins, f) absence of body malformation with pericardial edema and edema of the yolk sac.

most sensitive to metal exposure. Metals affect the embryos causing alterations during the organogenesis stage, inducing different malformations and mortality in embryos.

The malformations recorded in this study were reported in other studies using different chemical compounds such as mercury chloride $\left(\mathrm{HgCl}_{2}\right)$ (González 2005, Rivera 2006, Gaytán et al. 2008), and non-steroidal anti-inflammatory drugs (NAIDS) (Rodríguez-Anaya 2016). Our findings demonstrated that $\mathrm{Cr}$ (VI) caused damage in the spine and skeletal system in zebrafish embryos in the present study. In contrast, Gad (2014) established that chromium is a potent teratogen and primarily affecting the bone formation and Çoban et al. (2013) suggest that Cr (VI) increases deformities in fish tissue. These effects and the anomalies observed can be attributed to inhibition of DNA synthesis as a result of excessive levels of chromium (Kusch et al. 2007, Boglione et al. 2013,
Sfakianakis et al. 2015), causing dysregulation of matrix metalloproteinases (MMPs) (Hillegas et al. 2008), which are critical for normal zebrafish embryonic development.

In addition to spine malformations, pericardial edema and yolk sac edema were common malformations in zebrafish embryos exposed to potassium dichromate. This aspect is of particular interest. It is a piece of clear evidence that potassium dichromate can affect the heart development of zebrafish embryos. Many studies in zebrafish have been reported that pericardial edema and yolk sac edema are common malformations in embryos exposed to different toxicants (Hill et al. 2005, Raldúa et al. 2008, Ghobadian et al. 2015). Chemical compounds can decrease zebrafish embryos' heartbeats and cause pericardial edema ( $\mathrm{Yu}$ et al. 2011). These edemas are often associated with leaks in the endothelial vessels and usually result in cardio-vascular dysfunctions 


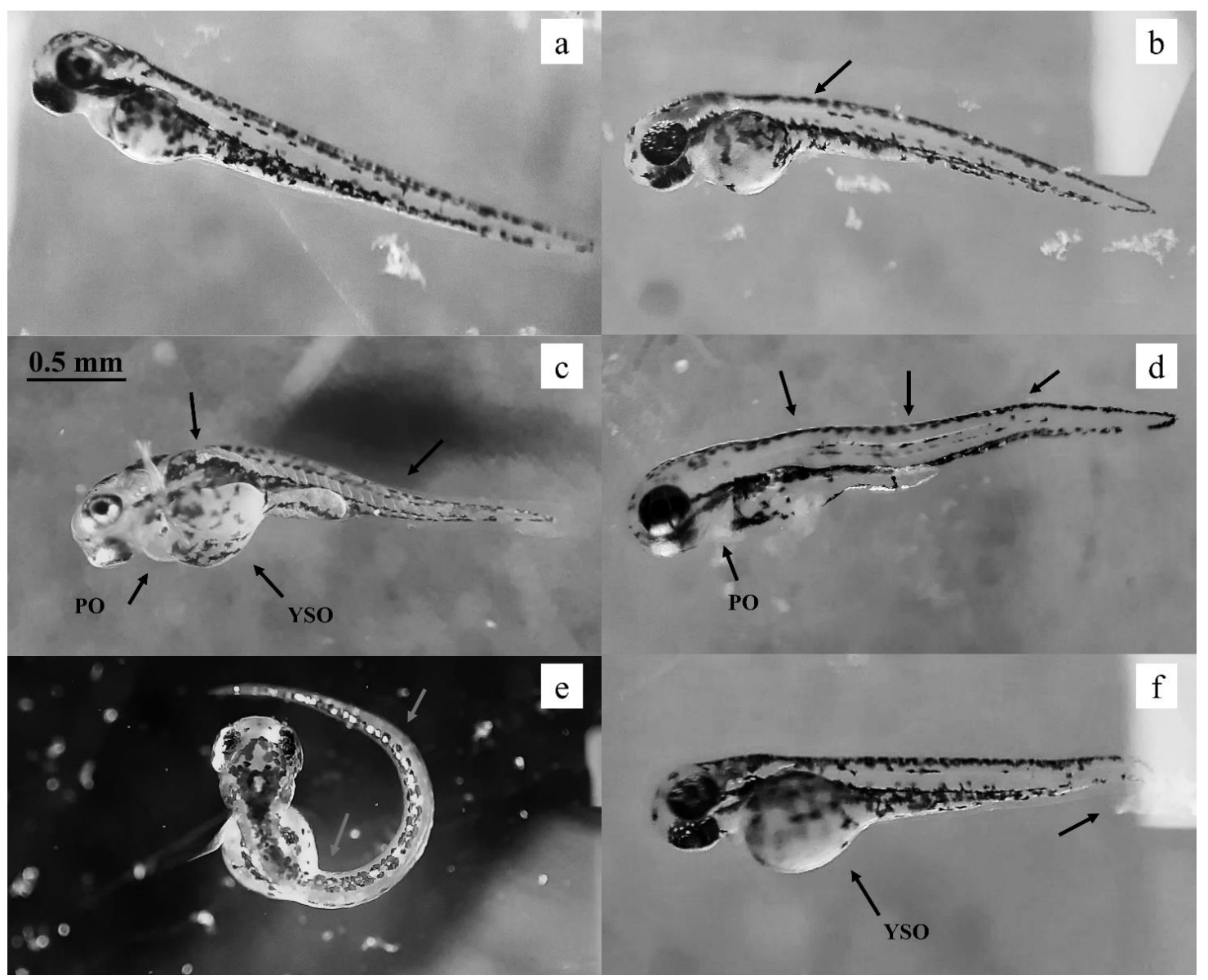

Figure 5. Late malformations in zebrafish Danio rerio embryos. PO: pericardial edema, YSO: yolk sac edema. a) Embryo with normal development, b) single malformation, c) double malformation with yolk sac edema and pericardial edema, d) multiple malformations with pericardial edema, e) curved malformation, f) malformation in fin with yolk sac edema.

(Hallare et al. 2005). The yolk sac's abnormal development is likely to result in an impaired nutritional supply of zebrafish embryos (Raldúa et al. 2008). These deformities in evaluating teratogenic effects represent an association since they usually occur in these studies of exposure to contaminants.

\section{CONCLUSIONS}

The effects of chromium on zebrafish Danio rerio embryos were assessed using the DarTA test. This study demonstrated that chromium exposure causes abnormal embryonic development and teratogenic effects, including severe heart defects in zebrafish embryos. Therefore, we conclude that potassium dichromate is toxic to the developmental stages of zebrafish. The finding that potassium dichromate is teratogenic in zebrafish embryos suggests that this metal should be tested and evaluate potential risk in mammalian systems. The present study results enriched our knowledge of potassium dichromate's influence on zebrafish embryonic development and provided the opportunity to understand chromium's mechanism of action. At the same time, this information may be taken into account in the development or modification of environmental strategies considering that heavy metals may appear in different environmental matrices from different sources and may cause adverse effects, as presented in this research.

\section{ACKNOWLEDGMENTS}

Thanks to the National Council of Science and Technology (CONACyT) for the first author's doctoral studies scholarship.

\section{REFERENCES}

Agency for Toxic Substances and Disease Registry (ATSDR). 2000. Chromium (TP-7) in toxicological profile. US Department of Health and Human Services, Washington DC. 
Bambino, K. \& Chu, J. 2016. Zebrafish in toxicology and environmental health. In: Sadler, K.C. (Ed.). Current topics in developmental biology. Elsevier, Amsterdam, pp. 331-367. doi: 10.1016/bs.ctdb.2016.10.007

Begum, G., Rao, J.V. \& Srikanth, K. 2006. Oxidative stress and changes in locomotor behavior and gill morphology of Gambusia affinis exposed to chromium. Toxicological \& Environmental Chemistry, 88: 355365. doi: 10.1080/02772240600635985

Boglione, C., Gisbert, E., Gavala, P., Witten, E., Moren, P., Fontagné, M. \& Koumoundouros, G. 2013. Skeletal anomalies in reared European fish larvae and juveniles. Part 2: Main typologies, occurrences and causative factors. Reviews in Aquaculture, 5: 51215167. doi: 10.1111/raq.12016

Çoban, M.Z., Eroğlu, M., Canpolat, O., Calta, M. \& Sen, D. 2013. Effect of chromium on scale morphology in scaly carp (Cyprinus carpio L.). Journal of Animal and Plant Sciences, 23: 1455-1459.

De Lemos, C.T., Rodel, P.M., Terra, N.R. \& Erdtmann, B. 2001. Evaluation of basal micronucleus frequency and hexavalent chromium effects in fish erythrocytes. Environmental Toxicology and Chemistry, 20: 13201324. doi: 10.1002/etc.5620200621

Domingues, I., Oliveira, R., Lourenço, J., Grisolia, C., Mendo, S. \& Soares, A. 2010. Biomarkers are a tool to assess chromium effects (VI): comparison of responses in zebrafish early life stages and adults. Comparative Biochemistry and Physiology - Part C: Toxicology \& Pharmacology, 152: 338-345. doi: 10.1016/j.cbpc.2010.05.010

Gad, S.C. 2014. Chromium. In: Wexler, P. (Ed.). Encyclopedia of toxicology. Academic Press, Cambridge, pp. 952-954.

Gaytán, O.J.C., González, L.L., Pulido-Flores, G., Monks, S., Gordillo-Martínez, A.J., Cabrera-Cruz, R.B.E. \& Pérez-Cruz, E. 2008. Evaluación de la calidad del agua en la Reserva de la Biosfera Barranca de Metztitlán, Hidalgo, México, a través de la inducción de malformaciones en columna vertebral en pez cebra (Danio rerio Hamilton, 1982). In: Pulido-Flores, G., LópezEscamilla, A.L. \& Pulido-Silva, M.T. (Eds.). Estudios biológicos en las áreas naturales del Estado de Hidalgo. Universidad Autónoma del Estado de Hidalgo, Pachuca de Soto, pp. 117-124.

Ghobadian, M., Nabiuni, M., Parivar, K., Fathi, M. \& Pazooki, J. 2015. Toxic effects of magnesium oxide nanoparticles on early developmental and larval stages of zebrafish (Danio rerio). Ecotoxicology and Environmental Safety, 122: 260-267. doi: 10.1016/ j.ecoenv.2015.08.009

González, L.L. 2005. Evaluación del efecto del cloruro de mercurio $\left(\mathrm{HgCl}_{2}\right)$ en la inducción de malformaciones de columna vertebral del pez cebra (Danio rerio Hamilton, 1982) durante diferentes etapas del desa- rrollo embrionario. Tesis de Licenciatura, Universidad Autónoma del Estado de Hidalgo, Pachuca de Soto.

Guertin, J. 2005. Toxicity and health effects of chromium (all oxidation states). In: Guertin, J., Jacobs, J.A. \& Avakian, C.P. (Eds.). Chromium (VI) handbook. CRC Press, Boca Raton, pp. 216-223.

Hallare, A.V., Schirling, M., Luckenbach, T., Kohler, H.R. \& Triebskorn, R. 2005. Combined temperature and cadmium effects on developmental parameters and biomarker responses in zebrafish (Danio rerio) embryos. Journal of Thermal Biology, 30: 7-17. doi: 10.1016/j.jtherbio.2004.06.002

Hill, A.J., Teraoka, H., Heideman, W. \& Peterson, R.E. 2005. Zebrafish as a model vertebrate for investigating chemical toxicity. Toxicological Sciences, 86: 6-19. doi: 10.1093/toxsci/kfi110

Hillegass, J.M., Villano, C.M., Cooper, K. \& White, L.A. 2008. Glucocorticoids alter craniofacial development and increase expression and activity of matrix metalloproteinases in developing zebrafish (Danio rerio). Toxicological Sciences, 102: 413-424. doi: 10.1093/toxsci/kfn010

Howe, K., Clark, M.D., Torroja, C.F., Berthelot, C. \& Muffato, M. 2013. The zebrafish reference genome sequence and its relationship to the human genome. Nature, 496: 498-503. doi: 10.1038/nature12111

International Agency for Research on Cancer (IARC). 1990. Chromium, nickel, and welding. IARC Monographs on the Evaluation of Carcinogenic Risk to Humans, 49: 1-648.

Incardona, J.P., Collier, T.K. \& Scholz, N.L. 2004. Defects in cardiac function precede morphological abnormalities in fish embryos exposed to polycyclic aromatic hydrocarbons. Toxicology and Applied Pharmacology, 196: 191-205. doi: 10.1016/j.taap. 2003.11.026

International Business Machines Corporation (IBM Corp.). 2017. IBM SPSS for Windows. Version 25.0. Armonk, New York.

Jezierska, B., Lugowska, K. \& Witeska, M. 2009. The effects of heavy metals on embryonic development of fish (a review). Fish Physiology and Biochemistry, 35: 625-640. doi: 10.1007/s10695-008-9284-4

Kimmel, C.B., Warga, R.M. \& Schilling, T.F. 1990. Origin and organization of the zebrafish fate map. Development, 108: 581-594.

Kimmel, C.B., Ballard, W.W., Kimmel, S.R., Ullmann, B. \& Schilling, T.F. 1995. Stages of embryonic development of the zebrafish. Developmental Dynamics, 203: 252-310. doi: 10.1002/aja.1002030302

Kusch, R.C., Krone, P.H. \& Chivers, D.P. 2007. Chronic exposure to low concentrations of waterborne cadmium during embryonic and larval development results in the long-term hindrance of antipredator behavior in 
zebrafish. Environmental Toxicology and Chemistry, 27: 705-710. doi: 10.1897/07-273.1

Li, Y., Yang, F., Chen, Z., Shi, L., Zhang, B., Pan, J., et al. 2014. Zebrafish on a chip: a novel platform for realtime monitoring of drug-induced developmental toxicity. Plos One, 9: 1-8. doi: 10.1371/journal.pone. 0094792

Lieschke, G.J. \& Currie, P.D. 2007. Animal models of human disease: zebrafish swim into view. Nature, 8: 353-367. doi: 10.1038/nrg2091

Lushchak, O.V., Kubrak, O.I., Nykorak, M.Z., Storey, K.B. \& Lushchak, V.I. 2008. The effect of potassium dichromate on free radical processes in goldfish: possible protective role of glutathione. Aquatic Toxicology, 87: 108-114, doi: 10.1016/j.aquatox. 2008.01.007

Mishra, A.K. \& Mohanty, B. 2008. Acute toxicity impacts of hexavalent chromium on behavior and histopathology of gill, kidney and liver of the freshwater fish, Channa punctatus (Bloch). Environmental Toxicology and Pharmacology, 26: 136-141. doi: 10.1016/j.etap. 2008.02.010

Mccollum, C.W., Ducharme, N.A., Bondesson, M. \& Gustafsson, J. 2011. Developmental toxicity screening in zebrafish. Birth Defects Research Part C: Embryo Today Reviews, 93: 67-114. doi: 10.1002/bdrc. 20210

Nagel, R. 2002. DarT: the embryo test with the zebrafish Danio rerio - a general model in ecotoxicology and toxicology. Altex, 19: 38-48.

Normann, C., Moreira, J.C.F. \& Cardoso, V.V. 2008. Micronuclei in red blood cells of armored catfish Hypostomus plecotomus exposed to potassium dichromate. African Journal of Biotechnology, 7: 893-896.

Organization for Economic Cooperation and Development (OECD). 2004. Guidelines for testing of chemicals. Guideline 202: Daphnia sp., acute immobilization test. OECD, Paris.

Oberamm, A. 2000. The use of a refined zebrafish embryo bioassay for the assessment of aquatic toxicity. Lab Animal, 29: 32-40.

Oliveira, R., Domingues, I., Grisolia, C.K. \& Soares, A.M. 2009. Effects of triclosan on zebrafish early-life stages and adults. Environmental Science and Pollution Research, 16: 679-688. doi: 10.1007/s11356-0090119-3

Oner, M., Atli, G. \& Canli, M. 2008. Changes in serum biochemical parameters of freshwater fish Oreochromis niloticus following prolonged metal $(\mathrm{Ag}, \mathrm{Cd}, \mathrm{Cr}, \mathrm{Cu}$, $\mathrm{Zn})$ exposures. Environmental Toxicology and Chemistry, 27: 360-366. doi: 10.1897/07-281R.1

Pica-Granados, Y., Trujillo-Domínguez, G., HernándezSalgado, H. \& González-Rebollar, S. 2011. Herramientas biológicas para el análisis de toxicidad y detección de efectos asociados a contaminantes, en sistemas acuáticos epicontinentales, costeros y aguas de uso antropogénico: desarrollo, adaptación y calibración de tecnologías. Informe 2012. Instituto Mexicano de Tecnología del Agua, Morelia.

Qi, W., Reiter, R.J., Tan, D.X., Garcia, J.J., Manchester, L.C., Karbownik, M. \& Calvo, J.R. 2000. Chromium (III)-induced 8-hydroxydeoxyguanosine in DNA and its reduction by antioxidants: comparative effects of melatonin, ascorbate, and vitamin E. Environmental Health Perspectives, 108: 399-402. doi: 10.1289/ehp. 00108399

Raldúa, D., André, M. \& Babin, P.J. 2008. Clofibrate and gemfibrozil induce an embryonic malabsorption syndrome in zebrafish. Toxicology and Applied Pharmacology, 228: 301-314. doi: 10.1016/j.taap.2007. 11.016

Rinkwitz, S., Mourrain, P. \& Becker, T.S. 2011. Zebrafish: an integrative system for neurogenomics and neurosciences. Progress in Neurobiology, 93: 231243. doi: 10.1016/j.pneurobio.2010.11.003

Rivera, I. 2006. Determinación de la frecuencia de malformaciones en columna vertebral, opérculo y aleta en Danio rerio Hamilton, 1822, como posibles bioindicadores en la valoración de daño teratogénico. Tesis de Licenciatura, Universidad Autónoma del Estado de Hidalgo, Pachuca de Soto.

Rodríguez-Anaya, A. 2016. Potencial de riesgo y efectos biológicos en Danio rerio por presencia en el ambiente de fármacos antiinflamatorios no esteroideos (AINEs) de alto consumo. Tesis de Doctorado, Universidad Autónoma del Estado de Hidalgo, Pachuca de Soto.

Samson, J.C. \& Shenker, J. 2000. The teratogenic effects of methylmercury on early development of the zebrafish, Danio rerio. Aquatic Toxicology, 48: 343354. doi: 10.1016/s0166-445x(99)00044-2

Sfakianakis, D.G., Ranieri, E., Kentouri, M. \& Tsatsakis, A.M. 2015. Effect of heavy metals on fish larvae deformities: a review. Environmental Research, 137: 246-255. doi: 10.1016/j.envres.2014.12.014

Sfakianakis, D.G., Georgakopoulou, E., Papadakis, I.E., Divanach, P., Kentouri, A. \& Koumoundouros, G. 2006. Environmental determinants of haemal lordosis in European sea bass, Dicentrarchus labrax (Linnaeus, 1758). Aquaculture, 254: 54-64. doi: 10.1016/j.aquaculture.2005.10.028

Shaw, P., Mondal, P., Bandyopadhyay, A. \& Chattopadhyay, A. 2019. Environmentally relevant concentration of chromium activates Nrf2 and alters transcription of related XME genes in liver of zebrafish. Chemosphere, 214: 35-46. doi: 10.1016/ j.chemosphere.2018.09.104

United States Environmental Protection Agency (USEPA). 2010. IRIS toxicological review of hexavalent chro- 
mium (2010 External Review Draft). EPA/635/R10/004A.2010. US Environmental Protection Agency, Washington, DC.

Valko, M., Morris, H. \& Cronin, M.T.D. 2005. Metals, toxicity and oxidative stress. Current Medicinal Chemistry, 12: 1161-1208. doi: 10.2174/09298670537 64635

Van Houcke, J., De Groef, L., Dekeyster, E. \& Moons, L. 2015. The zebrafish as a gerontology model in nervous system aging, disease, and repair. Ageing Research Reviews, 24: 358-368. doi: 10.1016/j.arr.2015.10.004

Velma, V., Vutukuru, S.S. \& Tchounwou, P.B. 2009. Ecotoxicology of hexavalent chromium in freshwater fish: a critical review. Reviews on Environmental Health, 24: 129-145. doi: 10.1515/review.2009.24. 2.129

Weigt, S., Huebler, N., Braunbeck, T., Von Landenberg, F. \& Broschard, T. 2010. Zebrafish teratogenicity test with metabolic activation $(\mathrm{m} D a r \mathrm{~T})$ : effects of phase I activation of acetaminophen on zebrafish Danio rerio embryos. Toxicology, 275: 36-49. doi: 10.1016/j.tox. 2010.05.012

Weil, M., Scholz, S., Zimmer, M., Sacher, F. \& Duis, K. 2009. Gene expression analysis in zebrafish embryos: a potential approach to predict effect concentrations in the fish early life-stage test. Environmental Toxicology and Chemistry, 28: 1970-1978. doi: 10.1897/08627.1

Westerfield, M. 2007. The zebrafish book. A guide for the laboratory use of zebrafish (Danio rerio). University of Oregon Press, Oregon.

Received: 13 May 2020; Accepted: 17 December 2020
World Health Organization (WHO). 2003. Chromium in drinking-water background document for development of WHO guidelines for drinking-water quality. World Health Organization, Ginebra.

Yang, F., Chen, Z., Pan, J., Li, X., Feng, J. \& Yang, H. 2011. An integrated microfluidic array system for evaluating toxicity and teratogenicity of drugs on embryonic zebrafish developmental dynamics. Biomicrofluidics, 5: 24115. doi: 10.1063/1.3605509

Yu, Y.L., Li, H.L., Wang, Y.C. \& Qiao, X.G., 2011. The effect of thiram on heart development of zebrafish embryos. Journal of Inner Mongolia University for Nationalities, 3: 1-7.

Zada, D., Tovin, A., Lerer-Goldshtein, T., Vatine, G.D. \& Appelbaum, L. 2014. Altered behavioral performance and live imaging of circuit-specific neural deficiencies in a zebrafish model for psychomotor retardation. Plos Genetics, 10: e1004615. doi: 10.1371/journal.pgen. 1004615

Zhang, C., Willett, C. \& Fremgen, T. 2003. Zebrafish: an animal model for toxicological studies. Current Protocols in Toxicology, 17: 1.7.1-1.7.18 doi: 10.1002/ 0471140856.tx0107s17

Zhu, Y., Wang, J., Bai, Y. \& Zhang, R. 2004. Cadmium, chromium, and copper induce polychromatocyte micronuclei in carp (Cyprinus carpio L.). Bulletin of Environmental Contamination and Toxicology, 72: 78-86. doi: 10.1007/s00128-003-0243-6 